\title{
Analysis of the influence factors of service outsourcing industry based on grey relational evaluation method -- a case study of Langfang City
}

\author{
Dong Zhen ${ }^{1, a}$ \\ 1.Hebei University of Technology, LangFang Hebei, 065000 China \\ a.Email: 962061430@qq.com
}

Keywords: Langfang grey correlation service outsourcing influencing factors

\begin{abstract}
With the rapid development of economic globalization and information technology, service outsourcing has been booming, thus undertake service outsourcing market competition is increasingly fierce. If want to win in the competition, recognizing the main factors influencing the development of service outsourcing and its actual state is particularly important. This paper uses grey correlation analysis method, the selection influence the development of service outsourcing industry in Langfang City 8 influencing factors, and the eight factors the influence degree of Langfang City to undertake service outsourcing ability, finally, analyzing according to the ranking order of service outsourcing industry in Langfang City in order to aspects such as policy to provide the reference.
\end{abstract}

\section{Grey Correlation Model}

Grey system theory is a system science theory (Grey Theory) initiated by the famous scholar ---Professor Deng Julong in 1982, wherein the grey correlation analysis is the method used for judging the correlation degree of the factors according to the similarity level of the geometrical shapes of the factor variation sequence curves, and this method aims at comparing the geometrical relationship among the statistical data related to the time sequences in the system through the quantitative analysis of the dynamic process development tendency. Specifically, if the curves are more similar to each other, then the corresponding sequences are more correlated to each other; oppositely, the corresponding sequences are less correlated to each other. Since the service outsourcing industry is developed only for more than ten years and is even an emerging industry in Langfang City, thus it is difficult to uniformly obtain the corresponding statistical data and meanwhile the massive data cannot be found for data processing and analysis. However, the sample capacity is not strictly required in the grey correlation analysis method and can be reduced to four samples; moreover, this method is also applicable to irregular data and can obtain relatively accurate result even when there are less data samples.

Step I: determine the analysis sequence

Determine the reference sequence reflecting the system behavior characteristics and the comparison sequences influencing the system behaviors, wherein the data sequence reflecting the system behavior characteristics is called as the reference sequence and is recorded as X0; the data sequence composed of the factors influencing the system behaviors is called as the comparison sequence and is recorded as Xij $(i=1, \ldots, m ; j=1, \ldots, n)$.

Step II: adopt the dimensionless method to process the reference sequence and the comparison sequence. 
The system factors have different meanings and the data dimensions may be different from each other, so it is inconvenient to compare these factors. During the grey correlation analysis, it is necessary to adopt the dimensionless method for data processing, such as initialization, equalization and interval valuation, wherein the initialization processing method is as follows:

$$
\begin{aligned}
& X_{0}=\left(1, \frac{X_{0}(2)}{X_{0}(1)}, \ldots, \frac{X_{0}(k)}{X_{0}(1)}, \ldots, \frac{X_{0}(n)}{X_{0}(1)}\right) \\
& X_{i}=\left(1, \frac{X_{i}(2)}{X_{i}(1)}, \ldots, \frac{X_{i}(k)}{X_{i}(1)}, \ldots, \frac{X_{i}(n)}{X_{i}(1)}\right), i=1, \ldots, m
\end{aligned}
$$

Step III: find the grey correlation coefficients of the reference sequence and the comparison sequences.

Find the difference sequences between the reference sequence and various comparison sequences:

$$
\Delta_{i}(k)=\left|X_{0}(k)-X_{i}(k)\right|
$$

Find the two-level minimum differences and maximum differences:

$$
\min _{i}\left(\min _{k}\left|X_{0}(k)-X_{i}(k)\right|\right) \max _{i}\left(\max _{k}\left|X_{0}(k)-X_{i}(k)\right|\right)
$$

Find the correlation coefficients:

$$
\xi_{i}(k)=\frac{\min _{i}\left(\min _{k}\left|X_{0}(k)-X_{i}(k)\right|\right)+\rho \max _{i}\left(\max _{k}\left|X_{0}(k)-X_{i}(k)\right|\right)}{\left|X_{0}(k)-X_{i}(k)\right|+\rho \max _{i}\left(\max _{k}\left|X_{0}(k)-X_{i}(k)\right|\right)}
$$

Where $\rho(0<\rho<1)$ is the resolution factor usually set as 0.5 .

Step IV: calculate the correlation degrees of various indexes.

$$
R_{i}=\frac{1}{n} \sum_{k=1}^{n} \xi_{i}(k)
$$

$\mathrm{Ri}$ value is used for judging the degree of the influence of the ith independent variable on the reference sequence. Larger $\mathrm{Ri}$ value indicates the larger correlation degree, and smaller Ri value indicates the smaller correlation degree. Finally, $\mathrm{Ri}$ is calculated for ranking in order to obtain the degree of the influence of the comparison sequence variables on the reference sequence variable.

\section{Establishment and Empirical Analysis of Influencing Factor Index System of Service Outsourcing Industry in Langfang City}

Although certain deviation exists due to the absence of the special statistical data, yet the data can still overall reflect the development situation of the service outsourcing industry in Langfang City in recent several years. During the comparison sequence index selection, it is difficult to quantitatively analyze such indexes as government support, legal environment and cultural environment; meanwhile, the data related to such indexes as service outsourcing population and regional extroversion are lacked or incomplete, and the multi-year quantitative analysis cannot be implemented, so these indexes should not be included in the index system.

With the consideration to data availability, measurability and representativeness, the following eight important factors influencing the development of the service outsourcing industry in Langfang City are determined through the investigation and analysis of the service outsourcing industry in Langfang City: "regional economic development level”, "service industry development level”, "infrastructure construction”, “outsourcing park development level”, "scientific and technological 
development level”, “external openness”, “talent reserve” and "human cost”. Additionally, the following eight quantity indexes are selected to respectively represent the data statistic indexes of the corresponding eight influencing factors: "regional per capita GDP", "added value of service industry”, “Internet user number”, “added value of high and new technology industry”, "patent application quantity”, "total export-import volume”, "number of students in colleges and technical secondary schools" and "average wage of on-the-job staff in cities and towns".

Table 1 Influencing Factors of Service Outsourcing Industry in Langfang City

\begin{tabular}{|c|c|c|}
\hline First-level Factor & Second-level Factor & Evaluation Index \\
\hline \multirow[t]{5}{*}{ Industrial development foundation } & Service outsourcing industry development & $\mathrm{X} 0$ added value of high and new technology \\
\hline & level & industry \\
\hline & Regional economic development level & X1 regional per capita GDP \\
\hline & Service industry development level & X2 added value of service industry \\
\hline & Infrastructure construction & X3 Internet user number \\
\hline \multirow{3}{*}{ External openness } & External openness & X4 total export-import volume \\
\hline & Scientific and technological development & X5 patent application quantity \\
\hline & level & \\
\hline \multirow[t]{4}{*}{ Technological innovation and manpower } & Talent reserve & X6 number of students in colleges and technical \\
\hline & Human cost & secondary schools \\
\hline & & $\mathrm{X} 7$ average wage of on-the-job staff in cities and \\
\hline & & towns \\
\hline
\end{tabular}

\section{Description for index system}

Industrial development foundation indexes

The industrial development foundation indexes include the following four second-level indexes, namely: service outsourcing industry development level, regional economic development level, service industry development level and infrastructure construction. Specifically, service outsourcing industry development: the service outsourcing industry is an emerging industry developed in recent several years in Langfang City, so relevant data are lacked or incomplete or non-uniform. Regional economic development level: the growth of the regional economic aggregate can most intuitively represent the regional economic development level, but in consideration of the population growth, per capita GDP is adopted in this paper to represent the economic development level of Langfang City in order to better represent the regional economic development level. Service industry development level: the service industry development level has gradually become an important index for evaluating whether a country is a developed country, and the service outsourcing is an important part of the modern service industry. Infrastructure construction: as the important foundation for the development of the urban industry and the service industry, the infrastructure construction can significantly influence such aspects as foreign investment attraction, economic development and people's life.

External openness:

In this paper, a second-level index ---- external openness is adopted to represent the regional external openness. As an important part of the service outsourcing, the offshore outsourcing is an important approach for participating in international cooperation and labor division. Foreign cooperation development and overseas market exploration can strengthen the bidding-contracting capability and the international competitiveness of an enterprise. In the project, the total export-import volume of Langfang City is adopted to represent the external openness. 
Technological innovation and manpower:

In this paper, the number of the students in colleges and technical secondary schools is adopted to represent the talent reserve. Human cost: along with the improvement of the economic level of the developed regions and cities at home and abroad, the office cost and the human cost are both continuously increased. The service outsourcing enterprises are featured with high added value for knowledge and the human cost is an important part of the total costs, so the average wage of on-the-job staff in cities and towns are adopted therein to represent the human cost.

Empirical grey correlation analysis of the service outsourcing industry in Langfang City

The grey correlation analysis method is adopted in this paper and EXCEL software is adopted for data processing. The correlation degrees between the seven comparison variables and the reference variable are calculated to finally rank the degrees of the influence of various indexes on the service outsourcing industry development in Langfang City.

Acquisition of original data

The data for the time sequence for the eight years from 2007 to 2014 are collected in this paper, wherein these data are sourced from the Statistical Yearbook of Langfang City for past years, the Statistical Bulletin for National Economic and Social Development of Langfang City, the government work reports for past years, ChinaSourcing Website, and the websites of the Commerce Department, the National Bureau of Statistics of the People's Republic of China, Langfang Bureau of Commerce, Langfang Government, etc.

Table 2 Influencing Factor Index Data Table for Service Outsourcing Industry in Langfang City

\begin{tabular}{|c|c|c|c|c|c|c|c|c|}
\hline \multirow[t]{7}{*}{ Index } & Regional Per & Added & Internet User & & Patent & Number of & Average Wage of & Added Value of \\
\hline & Capita GDP & Value of & Number of the & Total & Application & Students in & On-the-job Staff & Large-scale High \\
\hline & (Yuan) & Service & Whole City & Export-import & Quantity & Colleges and & in Cities and & and New \\
\hline & & Industry & (Household) & Volume & (PCS) & Technical & Towns (Yuan) & Technology \\
\hline & & (Hundred & & (Hundred & & Secondary & & Industry (100 \\
\hline & & Million & & Million & & Schools (Ten & & Million Yuan) \\
\hline & & Yuan) & & Dollars) & & Thousand) & & \\
\hline Variable & $\mathrm{X} 1$ & $\mathrm{X} 2$ & $\mathrm{X} 3$ & $\mathrm{X} 4$ & X5 & X6 & $\mathrm{X} 7$ & $\mathrm{X} 0$ \\
\hline 2007 & 21903 & 262.2 & 228916 & 23.6 & 559 & 7.85 & 14914 & 54.6 \\
\hline 2008 & 25757 & 326.6 & 282775 & 35.6 & 675 & 7.60 & 28873 & 112.3 \\
\hline 2009 & 25753 & 396.3 & 379579 & 33.7 & 1064 & 7.92 & 31472 & 147.5 \\
\hline 2010 & 31843 & 461.5 & 538750 & 48.0 & 1124 & 7.77 & 37224 & 193.5 \\
\hline 2011 & 36790 & 557.6 & 692955 & 52.9 & 1326 & 7.70 & 39976 & 254.5 \\
\hline 2012 & 40585 & 627.0 & 724155 & 50.3 & 1919 & 7.13 & 45061 & 341.2 \\
\hline 2013 & 44855 & 718.2 & 785630 & 59.0 & 2250 & 8.14 & 48994 & 133.2 \\
\hline 2014 & 48407 & 855.2 & 826516 & 52.9 & 2965 & 12.54 & 55536 & 139.3 \\
\hline
\end{tabular}

Data source: the Statistical Yearbook of Langfang City, the Statistical Bulletin for National Economic and Social Development of Langfang City, and relevant government websites.

Empirical analysis process

Step I: determine the analysis sequence: please refer to above Table 2 for the details, wherein the reference sequence is $\mathrm{X} 0$ (added value of high and new technology industry), and the comparison sequences are $\mathrm{X} 1, \mathrm{X} 2, \mathrm{X} 3, \ldots, \mathrm{X} 7$.

Step II: adopt the dimensionless method to process the reference sequence and the comparison sequences.

The initialization method is adopted in this paper for the dimensionless processing of the initial 
data, and the dimensionless data are as shown in Table 3:

Table 3 Dimensionless Data List

\begin{tabular}{lllllll}
\hline$\Delta_{1}(k)$ & $\Delta_{2}(k)$ & $\Delta_{3}(k)$ & $\Delta_{4}(k)$ & $\Delta_{5}(k)$ & $\Delta_{6}(k)$ & $\Delta_{7}(k)$ \\
\hline 0 & 0 & 0 & 0 & 0 & 0 & 0 \\
0.88081 & 0.811163 & 0.821498 & 0.548302 & 0.849263 & 1.088624 & 0.12081 \\
1.52569 & 1.190024 & 1.043307 & 1.273499 & 0.798066 & 1.692548 & 0.591233 \\
2.09013 & 1.783849 & 1.190473 & 1.510058 & 1.533223 & 2.554147 & 1.048046 \\
2.98149 & 2.534551 & 1.634057 & 2.419647 & 2.289079 & 3.68028 & 1.980738 \\
4.39614 & 3.85778 & 3.085675 & 4.117728 & 2.816168 & 5.340804 & 3.227695 \\
0.39166 & 0.29957 & 0.992397 & 0.06044 & 1.585484 & 1.402618 & 0.853319 \\
0.341219 & 0.710346 & 1.059283 & 0.309757 & 2.752832 & 0.95383 & 1.172467 \\
\hline
\end{tabular}

Step III: calculate the difference sequences between the reference sequence and the comparison sequences.

Table 4 Difference Sequence List for Reference Sequence and Comparison Sequences

\begin{tabular}{llllllll}
\hline $\mathrm{X} 1$ & $\mathrm{X} 2$ & $\mathrm{X} 3$ & $\mathrm{X} 4$ & $\mathrm{X} 5$ & $\mathrm{X} 6$ & $\mathrm{X} 7$ & $\mathrm{X} 0$ \\
\hline 1 & 1 & 1 & 1 & 1 & 1 & 1 & 1 \\
1.175958 & 1.245614 & 1.235278 & 1.508475 & 1.207513 & 0.968153 & 1.935966 & 2.056777 \\
1.175775 & 1.511442 & 1.658158 & 1.427966 & 1.903399 & 1.008917 & 2.110232 & 2.701465 \\
1.453819 & 1.760107 & 2.353483 & 2.033898 & 2.010733 & 0.989809 & 2.49591 & 3.543956 \\
1.679679 & 2.126621 & 3.027115 & 2.241525 & 2.372093 & 0.980892 & 2.680434 & 4.661172 \\
1.852943 & 2.391304 & 3.163409 & 2.131356 & 3.432916 & 0.90828 & 3.021389 & 6.249084 \\
2.047893 & 2.73913 & 3.431958 & 2.500000 & 4.025045 & 1.036943 & 3.292879 & 2.439560 \\
2.210063 & 3.26163 & 3.610565 & 2.241525 & 5.304114 & 1.597452 & 3.723749 & 2.551282 \\
\hline
\end{tabular}

Find the two-level minimum difference and maximum difference:

$$
\min _{i}\left(\min _{k}\left|X_{0}(k)-X_{i}(k)\right|\right)=0 \max _{i}\left(\max _{k}\left|X_{0}(k)-X_{i}(k)\right|\right)=5.340804
$$

Find the correlation coefficients:

$\xi_{i}(k)=\frac{\min _{i}\left(\min _{k}\left|X_{0}(k)-X_{i}(k)\right|\right)+\rho \max _{i}\left(\max _{k}\left|X_{0}(k)-X_{i}(k)\right|\right)}{\left|X_{0}(k)-X_{i}(k)\right|+\rho \max _{i}\left(\max _{k}\left|X_{0}(k)-X_{i}(k)\right|\right)}$

Where $\rho(0<\rho<1)$ is the resolution factor usually set as 0.5 .

Step IV: calculate the correlation degrees of various indexes, $R_{i}=\frac{1}{n} \sum_{k=1}^{n} \xi_{i}(k)$

The following values are obtained through calculation:

$$
\begin{aligned}
& R_{1}=0.694810 R_{2}=0.708674 R_{3}=0.713102 \\
& R_{4}=0.742185 R_{5}=0.663613 R_{6}=0.622483 \\
& R_{7}=0.746654
\end{aligned}
$$

Obviously, the correlation degrees of the influencing factor indexes and the dependent variable 
can be ranked as follows:

$$
R_{7}>\mathrm{R}_{4}>R_{3}>R_{2}>R_{1}>R_{5}>R_{6}
$$

Step V: the influencing factors of the service outsourcing industry in Langfang City are ranked as follows:

Table 5 Ranking Table for Correlation Degrees of Influencing Factors of Service Outsourcing Industry in Langfang City

\begin{tabular}{|c|c|c|c|c|}
\hline First-level Factor & Second-level Factor & Evaluation Index & Correlation Degree & Ranking \\
\hline \multirow{5}{*}{$\begin{array}{l}\text { Industrial } \\
\text { foundation }\end{array}$} & Regional & $\mathrm{X} 1$ regional per capita GDP & 0.667371 & 5 \\
\hline & development level & X2 added value of service industry & 0.697047 & 4 \\
\hline & Service industry development & X3 Internet user number & 0.712664 & 3 \\
\hline & level & & & \\
\hline & Infrastructure construction & & & \\
\hline \multirow[t]{2}{*}{ External openness } & External openness & X4 total export-import volume & 0.720180 & 2 \\
\hline & $\begin{array}{l}\text { Scientific and technological } \\
\text { development level }\end{array}$ & X5 patent application quantity & 0.688043 & 6 \\
\hline \multirow{4}{*}{$\begin{array}{l}\text { Technological innovation } \\
\text { and manpower }\end{array}$} & Talent reserve & X6 number of students in colleges & 0.606119 & 7 \\
\hline & Human cost & and technical secondary schools & 0.754024 & 1 \\
\hline & & $\mathrm{X} 7$ average wage of on-the-job staff & & \\
\hline & & in cities and towns & & \\
\hline
\end{tabular}

\section{Empirical result analysis}

According to the grey correlation analysis of various factors influencing the service outsourcing industry in Langfang City, we can know that the correlation degrees of the influencing factors are ranked as follows: average wage of on-the-job staff in cities and towns $>$ total export-import volume $>$ Internet user number $>$ added value of service industry $>$ per capita GDP $>$ patent application quantity > number of students in colleges and technical secondary schools. According to the grey correlation analysis of various factors influencing the service outsourcing industry in Langfang City, we can know that the influencing factors are ranked as follows: average wage of on-the-job staff in cities and towns $>$ total export-import volume $>$ Internet user number $>$ added value of service industry $>$ per capita GDP $>$ patent application quantity $>$ number of students in colleges and technical secondary schools.

Industrial development foundation

According to the ranking, the index ---- Internet user number takes the third place, laterally indicating that the infrastructure construction level and the informatization level play an important foundation role in developing the service outsourcing. The information technology is taken as the important media for the development of most service outsourcing businesses, high international broadband Internet speed and large load capacity can guarantee the development of the service outsourcing industry. Additionally, convenient traffic and logistics, comfortable office and living environment and other high-level infrastructure construction are also favorable for attracting the outsourcing enterprises and talents. Specifically, various high-tech zones and industrial zones in Langfang City have many important industrial parks regarding software, bio-pharmaceuticals, modern logistics, etc., thus becoming the important bases for developing the service outsourcing industry in Langfang City.

External openness

According to the result of the grey correlation analysis, the total export-import volume takes the 
second place, thus indicating that the external openness has an important influence on the development of the regional service outsourcing. Along with the globalization development, the trade contact among different countries becomes more and more closed. As an inland city for a long time, Langfang City has relatively low external openness and low economic contribution. As the important service outsourcing contractees, the foreign enterprises are the important part of the service outsourcing. Therefore, it is necessary to make full use of the regional advantages and positively develop the offshore outsourcing so as to make efforts for actively seizing the international service outsourcing market.

Technological innovation and manpower

The patent application quantity has a backward ranking and takes the sixth place. Actually, Langfang City has good scientific and technological foundation and high scientific research level, so it is necessary to give play to its own advantages, continuously increase the research investment for relevant fields of the service outsourcing industry and especially strengthen the research on cloud computing and Internet of Things, thus to provide technical support for the outsourcing enterprises and occupy the leading position for the future development of the service outsourcing industry.

\section{Conclusion}

According to the grey correlation analysis of relevant influencing factors of the service outsourcing industry in Langfang City, the influence degrees of relevant factors are ranked in this paper for the macroscopic analysis of the factors influencing the development of the service outsourcing in Langfang City. Meanwhile, existing data are applied for the empirical analysis so as to provide references for the government to stipulate relevant policies.

\section{Reference}

[1] Jinyu Hu and Zhiwei Gao. Distinction immune genes of hepatitis-induced heptatocellular carcinoma[J]. Bioinformatics, 2012, 28(24): 3191-3194.

[2] Jinyu Hu, Zhiwei Gao and Weisen Pan. Multiangle Social Network Recommendation Algorithms and Similarity Network Evaluation[J]. Journal of Applied Mathematics, 2013 (2013).

[3] Yang J, Lin Y, Gao Z, et al. Quality Index for Stereoscopic Images by Separately Evaluating Adding and Subtracting[J]. PloS one, 2015, 10(12): e0145800.

[4] Jiang $\mathrm{D}, \mathrm{Xu} \mathrm{Z}, \mathrm{Lv} \mathrm{Z}$. A multicast delivery approach with minimum energy consumption for wireless multi-hop networks[J]. Telecommunication Systems, 2015: 1-12. 